\title{
Research on Control Property of Low-temperature Floor Radiant Heating System
}

\author{
Enfu Yang*
}

Baotou Railway Vocational \& Technical College, Baotou, 014040, P.R. China

\begin{abstract}
A new energy-efficient and comfortable heating system, low-temperature floor radiant heating system of floor radiation is increasingly applied to a wide range of housing construction. In the paper, establishing the model of radiant floor heating systems, the effect of outdoor temperature, enclosure structures and heating storage characteristics that influence the indoor air temperature and the enclosure temperature, have been analyzed. The fuzzy-PID controller is chosen as the control radiant floor heating system. Several control strategies such as air-based control, slab-based control, and twoparameter control have been compared. Two-parameter control based on the floor surface temperature and the indoor air temperature is very stable, with high initial investment.
\end{abstract}

Keywords: Air-based control, Fuzzy-PID, The low-temperature floor radiant heating system, Two-parameter control.

\section{INTRODUCTION}

With the continuous improvement of living standards, people's requirements for comfort are also increasing, coupled with an increasing number of foreigners settled in China, the Chinese traditional heating methods are facing more and more challenges [1]. Low-temperature radiant floor heating will become the preferred way of heating because it's comfortable, healthy, environment friendly, and energy saving. As the key factor of low-temperature water radiant floor heating system, temperature control has become the study focus in HVAC industry.

The low-temperature radiant floor heating with features such as energy saving, environmental protection and comfort, by the introduction to our country, has gained great attention by other countries as well as the construction industry, and soon will be widely used in most parts of the North China.

As a new energy-efficient and comfortable heating system, low-temperature heating system of floor radiation is increasingly applied to a wide range of housing construction. Low-temperature radiant floor heating system is a system which makes use of the building ground to heat [2-4]. In the system, whole ground is used as a heat sink, and low temperature hot water is used as heat source. Through a plastic pipe which is high temperature and corrosion resistance, pressure is laid directly in the concrete layer. When the hot water flows into the aluminum tube, the released heat warms the floor uniformly. The floor warms the near air, and changes heat with body, wall, furniture and maintenance facilities around, raising these surfaces' temperature. In common, the temperature of water in low-temperature radiant floor heating system is below $60^{\circ} \mathrm{C}$; in home construction,

\footnotetext{
*Address correspondence to this author at the Baotou Railway Vocational \& Technical College, Baotou, 014040, P.R. China; Tel: 0086-18547209128; E-mail: yangenfu555@163.com
}

it is $30-50^{\circ} \mathrm{C}$ [3]. Radiation heat in the total transfer heat is more than $50 \%$. This heating method allows hot air distribution from the bottom to the top, meeting the characteristics of human physiology, solving the problem of space in heating, as an ideal heating system.

\section{LOW-TEMPERATURE WATER RADIANT FLOOR HEATING SYSTEM}

Along with the rapid development of the national economy and the improvement of modern living standards, lowtemperature water radiant floor heating technology is widely promoted and has become the preferred method of heating system. There are advantages with this system [5].

\subsection{Advantages}

It is comfortable and healthy. In terms of heating comfort, low-temperature radiant floor heating is an ideal way of heating, which allows hot air distribution from the bottom to the top, meeting the physical needs of the human body in temperature distribution. The temperature around is uniform, and the temperature gradually decreases from the bottom to the top, so that there is good feeling with cold head and warm feet. Because indoor air does not flow sharply, there are no indoor dust emissions. Hence, indoor air quality improves significantly, and people feel comfortable [6].

It is energy saving. Heating method of low-temperature radiant floor heating system is mainly thermal radiation, with little heat loss and high energy efficiency. In common, the temperature of water in low-temperature radiant floor heating system is below $60^{\circ} \mathrm{C}$. The boiler returns water, ground water and other waste energy can be effectively utilized in preparation energy, saving energy and protecting environment.

It saves space. Plastic pipe is buried below the floor, without any radiator and piping facilities in the room, so that it takes no effective interior space that increases the use of space. The indoor becomes more beautiful. 
It is good in thermal stability. Due to the great heat storage in floors and under-floor concrete layer, in the case of frequent opening of doors and windows, there is no significant change in the room temperature.

It can be used for a long time. The life of the system can be up to 50 years, instead of 15-20 years in the normal heating system.

\subsection{Disadvantages}

In the initial investment capital, the traditional way of heating is 35 to $38 \mathrm{CNY}$ per square meter, while the lowtemperature radiant floor heating system is $60 \mathrm{CNY}$ per square meter [7].

During the installation process, low temperature floor heating system has very strict requirements for the ground, pipe depth, pitch pipe and piping methods. The ground must be leveled, without any uneven and gravel pieces, steel and other installations. Small pipe buried deep will cause floor lower thermal resistance and high floor temperature. Different ways of piping has a great influence on the uniformity of surface temperature.

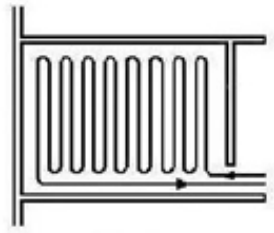

(a) Parallel piping

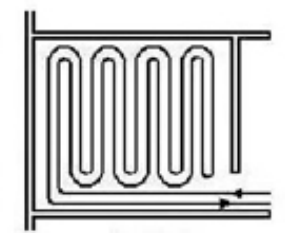

(b) Serpentine piping

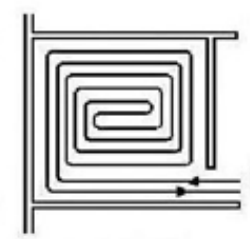

(c) vortex piping
Fig. (1). Ways of layout the tubes.

There are 3 ways of layout the tubes as shown in Fig. (1). The average temperature of floor surface reduces along the direction of water flow in parallel piping. Floor surface temperature changes dramatically in a small area, but the average temperature distribution is uniform in serpentine piping. The average temperature of floor surface reduces along the direction of water flow, and the average temperature distribution is more uniform in vortex piping. So the appropriate piping way and tube spacing are selected according to actual situation.

\section{MATHEMATICAL MODEL AND CONTROL OF} THE SYSTEM

Domestic and foreign scientists and engineers carried on a large number of researches about its heating mechanisms, thermal comfort and energy-saving effect areas. But most research has been focused on the internal structure of the floors and heat transfer process, from the simulation calculation of heat transfer model to establishing the internal floor, analyzing cover thickness and pipe distance, laying out ways and other factors for the system temperature distribution. As for the regulation and control of the floor heating, radiation is less involved, because radiation floor cover has capability of strong heat storage and the use of exothermic process. Thus, it needs further study on cover floor heating systems intermittent operation to establish a more realistic heat transfer model. This paper summed up the law of temperature change and provided a theoretical basis and practice guidance for designing, function and management of a floor heating model.

\subsection{Mathematical Model}

Radiant heat release of the floor is

$\mathrm{q}_{r}=J_{f}-\sum_{i=1}^{n} \phi_{f, i} J_{i}$

$\mathrm{q}_{r}$ is radiant transfer heat of the floor.

$J_{f}$ is the total radiant heat of the floor surfaces.

$J_{\mathrm{i}}$ is the total radiant heat of the surfaces $i$.

$\phi_{f, i}$ is Radiation angle factor of the surfaces $i$ to the floor.

The multi-surface room is simplified into two surfaces, floor surface and imaginary surface. Imaginary surface temperature is $t_{\text {AUST }}$ (Average Unheated Surface Temperature).

$\mathrm{t}_{r}=\frac{\sum_{i=1}^{n} A_{i} \varepsilon_{i} t_{i}}{\sum_{i=1}^{n} A_{i} \varepsilon_{i}}=t_{A U S T}$

$\mathrm{t}_{r}$ is the imaginary surface temperature, ${ }^{\circ} \mathrm{C}$.

$\mathrm{A}_{\mathrm{i}}$ is the surface area of the surface $\mathrm{i}$ in the room.

$\varepsilon_{\mathrm{i}}$ is the emissivity of the surface $i$ in the room.

$t_{i}$ is the average temperature of the surface $i$ in the room.

$\mathrm{t}_{\mathrm{AUST}}$ is average unheated surface temperature.

It is simplified into

$\mathrm{q}_{\mathrm{r}}=\sigma_{\mathrm{b}} \phi_{\mathrm{r}}\left[\left(\mathrm{t}_{\mathrm{f}}+273\right)^{4}-\left(\mathrm{t}_{\text {AUST }}+273\right)^{4}\right]$

$\mathrm{q}_{\mathrm{r}}$ is the radiant transfer heat of the floor after simplifying.

$\sigma_{\mathrm{b}}$ is the blackbody radiation constant.

$\phi_{\mathrm{r}}$ is considerable radiation angle coefficient between the floor and the imaginary surface.

$t_{f}$ is the average temperature of the floor surface.

Considerable radiation angle coefficient between the two surfaces is

$\phi_{\mathrm{r}}=\frac{1}{\left(\frac{1}{\varepsilon_{\mathrm{f}}}-1\right)+\frac{1}{\phi_{f, r}}+\frac{A_{f}}{A_{r}}\left(\frac{1}{\varepsilon_{\mathrm{f}}}-1\right)}$

$\varepsilon_{\mathrm{f}}, \varepsilon_{r}$ is emissivity of the floor surface and the imaginary surface.

$\phi_{f, r}$ is the angle factor of floor to imaginary surface.

$A_{\mathrm{f}}, A_{r}$ is the surface area of the floor surface and the imaginary surface.

$\mathrm{q}_{r}=5 * 10^{-8}\left[\left(t_{f}+273\right)^{4}-\left(t_{\text {AUST }}+273\right)^{4}\right]$

The radiant heat transfer relationship between radiant floor heating room floor and the non-heated surface is shown in Fig. (2). 


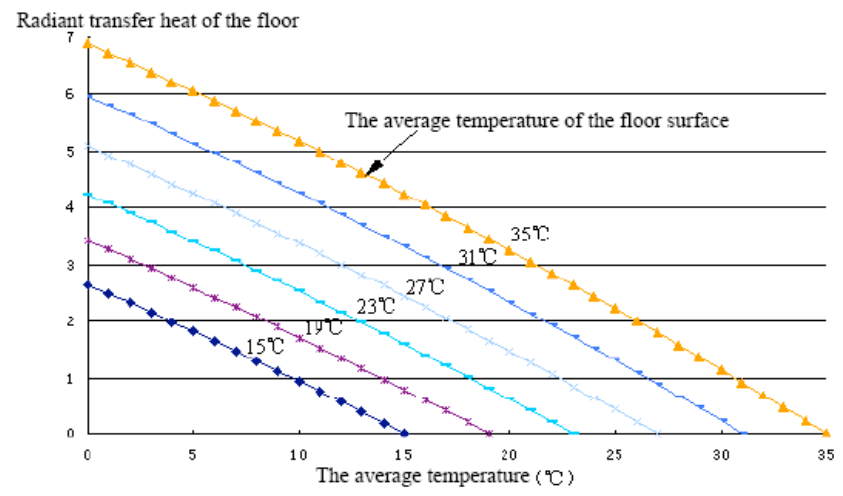

Fig. (2). The radiant heat transfer relationship between radiant floor heating room floor and the non-heated surface.

\subsection{Control}

\subsubsection{PID Controller}

PID control is shown as :

$\mathrm{u}(t)=k_{p}\left[e(t)+\frac{1}{T_{i}} \int_{0}^{t} e(t) d t+T_{d} \frac{d e(t)}{d t}\right]$

Low-temperature radiant floor heating system is a discrete system, so it is changed to:

$\mathrm{u}(\mathrm{k})=k_{p}\left\{e(k)+\frac{T}{T_{i}} \sum_{i=0}^{k} e(i)+\frac{T_{d}}{T}[e(k)-e(k-1)]\right\}$

$\mathrm{u}(\mathrm{k})$ is the output function of PID in time $\mathrm{k}$.

$\mathrm{e}(\mathrm{k})$ input function of PID in time $\mathrm{k}$.

$\mathrm{T}$ is the sampling period of the system.

$\mathrm{T}_{\mathrm{i}}$ is the integration time constant.

$\mathrm{T}_{\mathrm{d}}$ is the differential time constant.

$\mathrm{k}_{\mathrm{p}}$ is the scaling factor.

$\mathrm{u}(\mathrm{k})=k_{p} \mathrm{e}(k)+k_{i} \sum_{i=0}^{k} e(i)+k_{d}[e(k)-e(k-1)]$

$\Delta \mathrm{u}(\mathrm{k})=k_{p} \mathrm{e}(k)+k_{i} \sum_{i=0}^{k} e(i)+k_{d}[e(k)-e(k-1)]$

$-\left\{k_{p} \mathrm{e}(k-1)+k_{i} \sum_{i=0}^{k} e(i)+k_{d}[e(k-1)-e(k-2)]\right\}$

$=\mathrm{k}_{p} \Delta e(k)+k_{i} e(k)+k_{d}[\Delta e(k)-\Delta e(k-1)]$

$=\left(k_{p}+k_{i}+k_{d}\right) e(k)-\left(2 k_{d}+k_{p}\right) e(k-1)+k_{d} e(k-2)$

$=\mathrm{k}_{p}\left(1+\frac{T}{T_{i}}+\frac{T_{d}}{T}\right) e(k)-k_{d} \frac{T_{d}}{T} e(k-2)$

The PID controller parameters are fixed. The control is not optimal without online self-tuning. So, fuzzy-PID is developed.

\subsubsection{Fuzzy-PID}

The fuzzy-PID changes the PID controller parameters according to the fuzzy table of $\mathrm{kp}$, online adjusting the parameters, meeting the control requirements at different times [8].
The most important thing is to build the fuzzy rules in line with the actual situation, based on practical experience accumulated by people in the past. Three parameters are adjusted according to the fuzzy rule.

The block diagram of the fuzzy-PID controller is shown in Fig. (3).

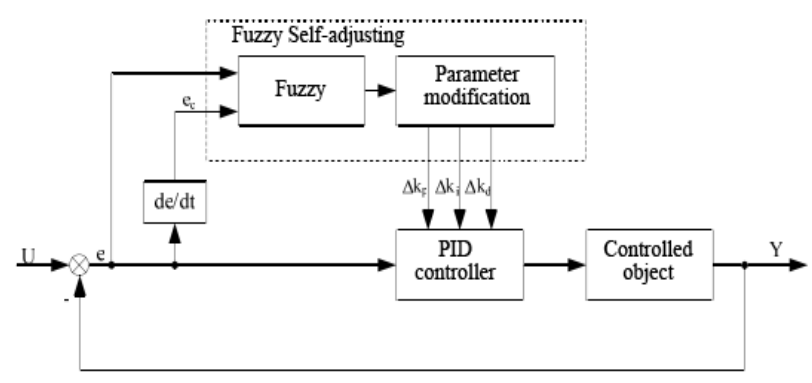

Fig. (3). The block diagram of the Fuzzy-PID controller.

\section{EXPERIMENT}

In a regulatory control period, the central vertical measuring point temperature in the middle of floor varies as shown in Fig. (4). Generally, we believed the temperature in $1.5 \mathrm{~m}$ above the room ground represents the average temperature indoors. The temperature in $1.5 \mathrm{~m}$ and $2.8 \mathrm{~m}$ above the room ground is the same, and $1^{\circ} \mathrm{C}$ lower than $0.3 \mathrm{~m}$ above the room ground. So in radiant floor heating room, the indoor temperature distribution in vertical is very uniform, with better comfort.

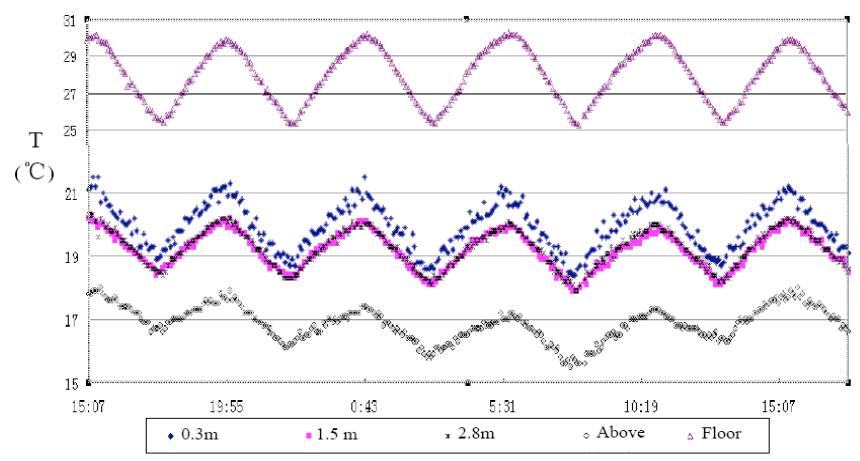

Fig. (4). Room temperature fluctuation in vertical.

The temperature of hot water is set to $50^{\circ} \mathrm{C}$. In the same water flow and the outdoor ambient temperature, the indoor temperature is set to $30^{\circ} \mathrm{C}$. PID and fuzzy-PID control are used to control the low-temperature radiant floor heating system. It is shown in Figs. $(\mathbf{5}, \mathbf{6})$.

The reference circulation pump control based on the indoor air temperature is shown in Table. The indoor temperature is set to $18-20^{\circ} \mathrm{C}$, so the temperature of the floor surface is $23 \sim 31^{\circ} \mathrm{C}$. In $24 \mathrm{~h}$, circulating pump starts 5 times, running for $12 \mathrm{~h}$. The maximum amplitude of the room temperature is under $3^{\circ} \mathrm{C}$. The reference circulation pump control based on the indoor air temperature can maintain temperature stability as shown in Table 1 and Fig. (7). 


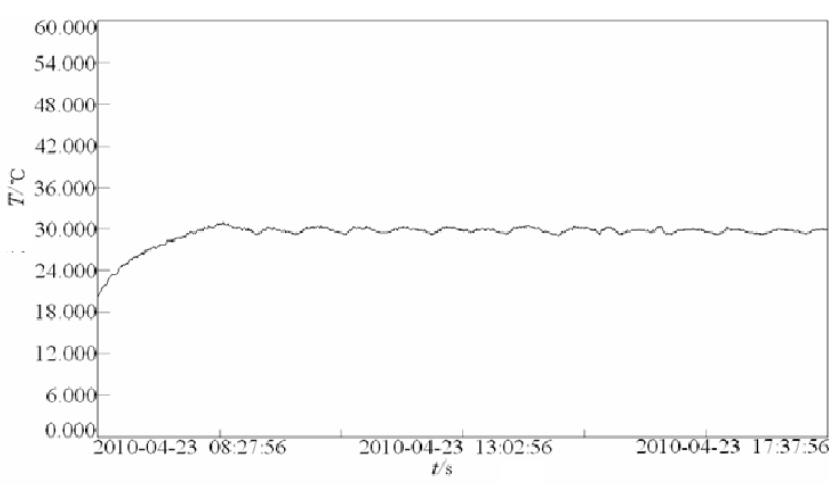

Fig. (5). Control effect diagram of PID.

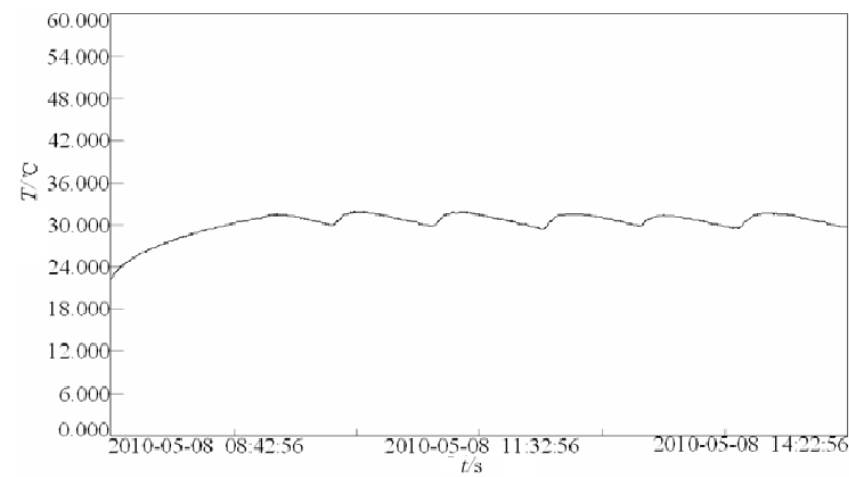

Fig. (6). Control effect diagram of Fuzzy-PID.

Table 1. The control based on indoor air temperature.

\begin{tabular}{|c|c|c|c|c|c|c|c|c|c|c|}
\hline & $14: 30$ & $16: 21$ & $19: 36$ & $21: 56$ & 00:39 & $03: 44$ & $05: 58$ & 09:42 & $12: 23$ & $14: 58$ \\
\hline The indoor temperature & 18 & 20 & 18 & 20 & 18 & 20 & 18 & 20 & 18 & 20 \\
\hline The controller & on & off & on & off & on & off & on & off & on & off \\
\hline
\end{tabular}

Table 2. The control based on the floor temperature.

\begin{tabular}{|c|c|c|c|c|c|c|c|c|}
\hline & $22: 44$ & $23: 58$ & $01: 48$ & 03:08 & 04:58 & $06: 12$ & 08:02 & 09:27 \\
\hline \multirow[t]{2}{*}{ The controller } & on & off & on & off & on & off & on & off \\
\hline & $11: 13$ & $12: 45$ & $14: 46$ & $16: 05$ & 18:00 & $19: 30$ & $21: 32$ & $22: 55$ \\
\hline The indoor temperature & 18.5 & 19.6 & 18.7 & 19.5 & 18.6 & 19.9 & 18.5 & 19.6 \\
\hline The controller & on & off & on & off & on & off & on & off \\
\hline
\end{tabular}

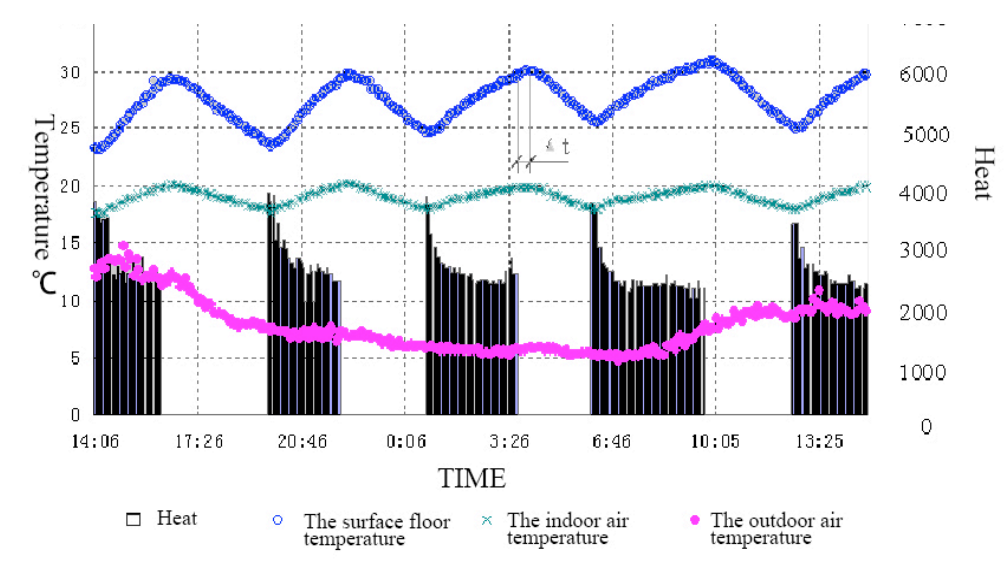

Fig. (7). The Start-stop control based on the indoor air temperature.

The reference circulation pump control based on the floor temperature is shown in Table 2 and Fig. (8). The floor temperature is set to $26-28^{\circ} \mathrm{C}$, so the temperature of the floor surface is $25 \sim 29^{\circ} \mathrm{C}$; the temperature of the indoor air is $18 \sim$ $20^{\circ} \mathrm{C}$. In the control of indoor air temperature, floor surface temperature fluctuation is large. In the control of floor temperature, indoor air temperature is stable. 


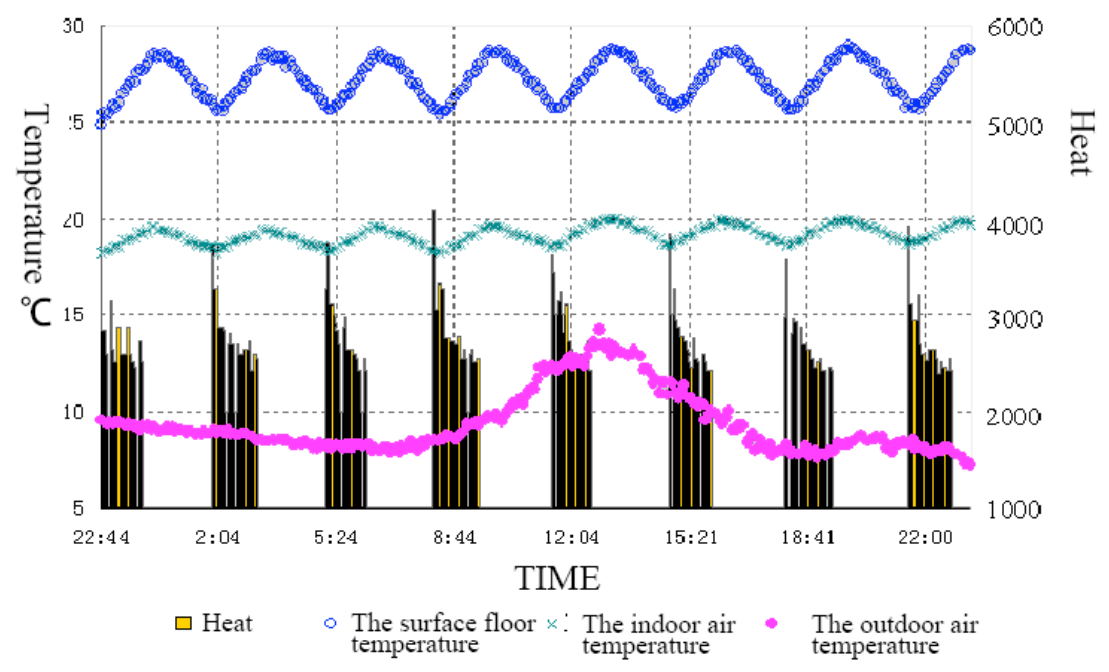

Fig. (8). The Start-stop control based on the floor temperature.

The control based on the indoor air temperature can basically meet the temperature requirements. The control based on the floor surface temperature is feasible in the short term, while the floor surface temperature needs to be adjusted in the whole heating period. Two-parameter control based on the floor surface temperature and the indoor air temperature is very stable, with high initial investment.

\section{CONFLICT OF INTEREST}

The author confirms that this article content has no conflict of interest.

\section{ACKNOWLEDGEMENTS}

Declared none.

\section{REFERENCES}

[1] A. Hasan, J. Kurnitski, and K. Jokiranta, "A combined low temperature water heating system consisting of radiators and floor heating," Energy and Buildings, vol. 41, no. 5, pp. 470-479, 2009.
[2] C. Verhelst, F. Logist, J. Van Impe, and L. Helsen, "Study of the optimal control problem formulation for modulating air-to-water heat pumps connected to a residential floor heating system," Energy and Buildings, vol. 45, pp. 43-53, 2012.

[3] A. Savran, "A multivariable predictive fuzzy PID control system," Applied Soft Computing, vol. 13, no. 5, pp. 2658-2667, 2013.

[4] Y. Hamada, H. Saitoh, M. Nakamura, H. Kubota, and K. Ochifuji "Field performance of an energy pile system for space heating," Energy and Buildings, vol. 39, no. 5, pp. 517-524, 2007.

[5] X. Jin, X. Zhang, Y. Luo, and R. Cao, "Numerical simulation of radiant floor cooling system: The effects of thermal resistance of pipe and water velocity on the performance," Building and Environment, vol. 45, no. 11, pp. 2545-2552, 2010.

[6] J. Rekstad, M. Meir, and A. R. Kristoffersen, "Control and energy metering in low temperature heating systems," Energy and Buildings, vol. 35, no. 3, pp. 281-291, 2003.

[7] J. Ren, L. Zhu, Y. Wang, C. Wang, and W. Xiong, "Very low temperature radiant heating/cooling indoor end system for efficient use of renewable energies," Solar Energy, vol. 84, no. 6, pp. 1072$1083,2010$.

[8] Z. Liying, and Z. Guoshu, "Application of fuzzy-PID control algorithm in uniform velocity temperature control system of resistance furnace," Chinese Journal of Scientific Instrument, vol. 29, no. 2, pp. 405, 2008.

Received: May 26, 2015

Revised: July 14, 2015

Accepted: August 10, 2015

(C) Enfu Yang; Licensee Bentham Open.

This is an open access article licensed under the terms of the (https://creativecommons.org/licenses/by/4.0/legalcode), which permits unrestricted, noncommercial use, distribution and reproduction in any medium, provided the work is properly cited. 